\title{
PRACTICE PATTERNS AMONG ENTRANTS AND INCUMBENTS IN THE HOME HEALTH MARKET AFTER THE PROSPECTIVE PAYMENT SYSTEM WAS IMPLEMENTED
}

\author{
HYUNJEE KIM ${ }^{\mathrm{a}, *}$ and EDWARD C. NORTON ${ }^{\mathrm{b}, \mathrm{c}, \mathrm{d}}$ \\ ${ }^{a}$ Center for Health Systems Effectiveness, Oregon Health and Science University, Portland, OR, USA \\ ${ }^{\mathrm{b}}$ Department of Health Policy and Management, University of Michigan, Ann Arbor, MI, USA \\ ${ }^{\mathrm{c}}$ Department of Economics, University of Michigan, Ann Arbor, MI, USA \\ ${ }^{\mathrm{d}}$ NBER, Cambridge, MA, USA
}

\begin{abstract}
Home health care expenditures were the fastest growing part of Medicare from 2001-2009, despite the implementation of prospective payment. Prior research has shown that home health agencies adopted two specific strategies to take advantage of Medicare policies: provide at least 10 therapy visits to get an enormous marginal payment and recertify patients for additional episodes. We study whether there is heterogeneity in the adoption of those strategic behaviors between home health agency entrants and incumbents and find that entrants were more likely to adopt strategic practice patterns than were incumbents. We also find that for-profit incumbents mimicked one of the practice patterns following entrants in the same market. Our findings suggest that it is important to understand the heterogeneity in providers' behavior and how firms interact with each other in the same market. These findings help explain the rapid rise in expenditures in the home health care market. Copyright @ 2015 John Wiley \& Sons, Ltd.
\end{abstract}

Received 28 February 2014; Revised 18 November 2014; Accepted 24 November 2014

KEY WORDS: entry strategy; home health care; long-term care

\section{INTRODUCTION}

During the last decade, home health care was the American Medicare-covered service that experienced the largest percentage increase in spending. Its annual real growth rate between 2001 and 2009 was $7.8 \%$, well above Medicare's annual growth rate of $3.7 \%$ during the same period. This dramatic increase in Medicare home health spending was surprising because it occurred under the prospective payment system (PPS) for home health services, which was introduced in October 2000 expressly to control rapidly rising expenditures.

Previous studies have found that one of the reasons for the expenditure growth was that home health agencies strategically adjusted their practice patterns under the new payment system (MedPAC, 2010, 2011, 2012). In particular, agencies exploited two features of the PPS. First, the non-linear pricing for therapy visits meant that the marginal revenue of the tenth visit, roughly $\$ 2000$, was almost twenty times higher than the average cost of one therapy visit. This led to a predictable clumping at 10 therapy visits and few patients with seven to nine visits. Second, vague guidelines gave home health agencies considerable leeway in deciding whether to renew treating patients after the initial capitated 60-day episode was over. Therefore, agencies could easily recertify

\footnotetext{
*Correspondence to: Center for Health Systems Effectiveness, Oregon Health and Science University, 3181 SW Sam Jackson Park Road, MDY 200K, Portland, OR 97239, USA. E-mail: kihy@ ohsu.edu
} 
additional episodes of care for patients. These features of the PPS increased the profit margins of the home health industry and attracted many new agencies to the market (MedPAC, 2010).

In this paper, we extend the research on the general response to PPS's financial incentives to understand how agencies' behavior changed in markets with high rates of entry. Entrants might be more responsive to the financial incentives than incumbents. Entrants might face lower adjustment costs because they do not have established practice patterns yet and can readily adopt practice patterns that lead to high profits. In contrast, incumbents might have established their own practice patterns over a long period of time and thus find it harder to adopt new practice patterns. We also study the difference between for-profit and nonprofit entrants. If for-profit entrants have a stronger profit motive, they are then expected to be more responsive to incentives.

In addition, we study the interaction between entrants and incumbents. Incumbents may have been less responsive to financial incentives because of their higher adjustment costs. However, in a market with strong competition from entrants, incumbents might be more likely to respond by changing their practice patterns. We predict that incumbents in a market where entrants more adroitly responded to the financial incentives will be more likely to resemble entrants' practice patterns.

Our empirical results suggest that entrants were more likely to adopt strategically savvy practice patterns (i.e., targeting a 10th therapy visit each episode and recertifying an episode of care) than incumbents. This result holds both for for-profit and nonprofit entrants. We also find that for-profit incumbents mimicked entrants in their market for one of those two behaviors (targeting a 10th therapy visit each episode).

\section{BACKGROUND}

Home health agencies provide both medical and non-medical services (skilled nursing, physical therapy, occupational therapy, speech therapy, home health aide, and medical social work visits) for Medicare patients in their home. To be eligible for home health services, Medicare beneficiaries must be home-bound and have a need for part-time (i.e., eight or fewer hours per day) or intermittent skilled care for their illnesses. A beneficiary's physician must also certify eligibility for home health care (MedPAC, 2011). About one-third of home health episodes were preceded by a hospitalization or other post-acute care (e.g., skilled nursing home) in 2010 (MedPAC, 2013). Importantly, Medicare patients have no out-of-pocket payments for home health services. There are neither deductibles nor copayments. Therefore, with no demand-side variation in price, it is essential to focus on the supply-side response to policy changes.

Home health care may at first seem to play a relatively minor role in the health system because of its relatively small spending. In 2011, home health expenditures accounted for only 3\% of total Medicare expenditures (MedPAC, 2013). However, home health care can be a close substitute for other more expensive health services, including hospital inpatient and nursing-home care. Therefore, it can exert a significant influence on total health expenditures (Lichtenberg, 2012; Benjamin, 1993). Also, a significant number of Medicare beneficiaries use home health services ( $8 \%$ of beneficiaries in 2010). Equally importantly, home health services enable patients to live at home rather than in a nursing home, which is strongly preferred (Konetzka, Karon, and Potter, 2012).

Medicare home health was reimbursed under the fee-for-service payment system until 1997. Home health spending soared under this system because Medicare reimbursed the actual home health charges almost with no limits. Many agencies also entered the market (Figure 1). Responding to the spending surge, Medicare introduced the interim payment system, which made payments more restrictive. This led to plummeting spending and bankruptcy for one-third of the agencies. Medicare then introduced the prospective payment system (PPS) for home health services in October 2000 (MedPAC, 2012, 2013). The PPS makes a risk-adjusted fixed payment for every 60-day episode of care (MedPAC, 2010; Ackerly and Grabowski, 2014). Prospective per-episode payments were expected to reduce unnecessary services and curb the historical trend in home health spending. However, unintended financial incentives enabled agencies to adopt new practice patterns and increase Medicare reimbursement greatly (MedPAC, 2010, 2012). Specifically, agencies used the two following strategies: 


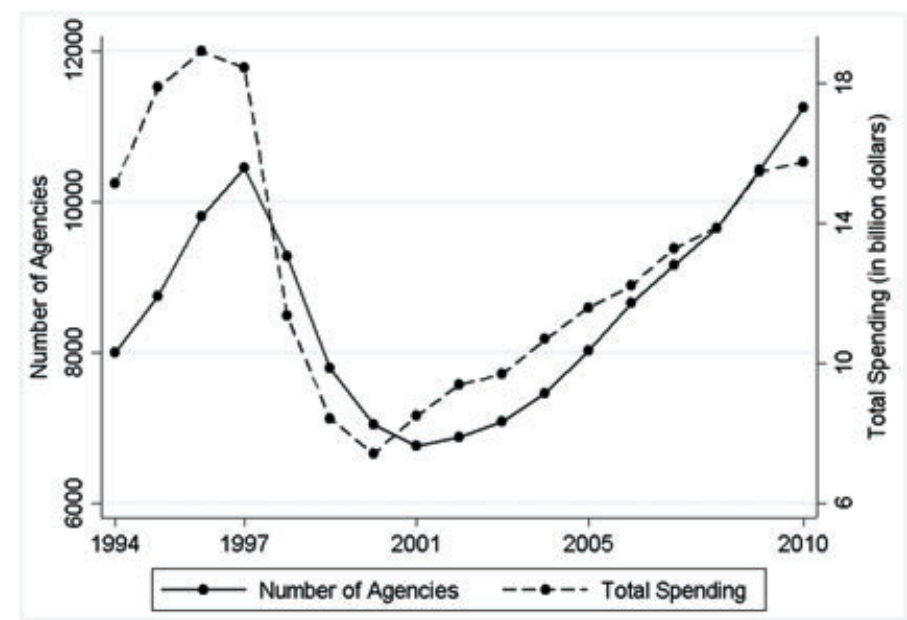

Figure 1. Medicare home health spending and number of agencies under the different payment systems. Source: Center for Medicare and Medicaid Services (CMS) statistical supplement \& CMS Provider of Services File. Notes: (1) Total spending is in 2001 real dollars. We adjusted for inflation using Consumer Price Index (CPI). (2) Both total spending and number of agencies increased under the fee-forservice payment system until 1997, decreased under the interim payment system between 1998 and 2000, and again increased under the prospective payment system from 2001

(1) targeting a tenth therapy visit each episode and (2) recertifying an episode of care (MedPAC, 2010, 2011, 2012). These strategies are the focus of this paper.

First, agencies responded to a moral hazard incentive embedded in the prospective payment schedule by strategically adjusting the number of therapy visits per episode. For the first four visits, reimbursement was proportional to the number of visits. The reimbursement jumped a bit for the fifth visit and remained constant through nine visits (zero marginal revenue for visits six through nine). However, the payment increased significantly for episodes with 10 visits or more-and here is where the PPS moral hazard incentive is striking. The marginal reimbursement was zero for visits beyond the 10th (unless the patient becomes a high-cost outlier patient). Agencies, of course, had a strong financial incentive to provide 10 visits to earn enormous marginal revenue (MedPAC, 2010). When the PPS was proposed, people were concerned about this moral hazard incentive. However, the Center for Medicare and Medicaid Services (CMS) decided to set a high marginal benefit for the tenth therapy visit to ensure that the CMS compensates agencies that provided expensive therapy visits for 'sick' patients. In particular, the CMS identified sick patients as those who received at least 10 therapy visits. Ten was chosen because one therapy visit lasts about $48 \mathrm{~min}$, and the definition of a high therapy case is one with at least 8 hours of therapy (HCFA, 2000).

For an example of how strong these incentives are, consider the reimbursement schedule for a typical patient who received physical therapy visits from an agency located in Ann Arbor, MI, in 2001 (Figure 2(a)). The marginal reimbursement for the fifth visit is more than $\$ 1000$, and for the 10 th visit, it is more than $\$ 2,000$, which is much higher than the average cost of one physical therapy visit (\$104.74 in 2001) (HCFA, 2000). The marginal reimbursement for all other visits after the 10th (until reaching modest outlier payments after the 56th visit) is zero.

Agencies responded to this financial incentive. There is a conspicuous peak at the 10th visit in the density distribution of the number of therapy visits provided (Figure 2(b)). Furthermore, the peak became more pronounced over time, presumably as agencies learned how to game the system. MedPAC (2012) also reported that the number of episodes with 10 or more visits increased almost twice as fast as all other episodes. This suggests that agencies were intentionally meeting the 10th-visit threshold. This targeting behavior continued until 2008 when Medicare revised the reimbursement schedule for therapy visits. 


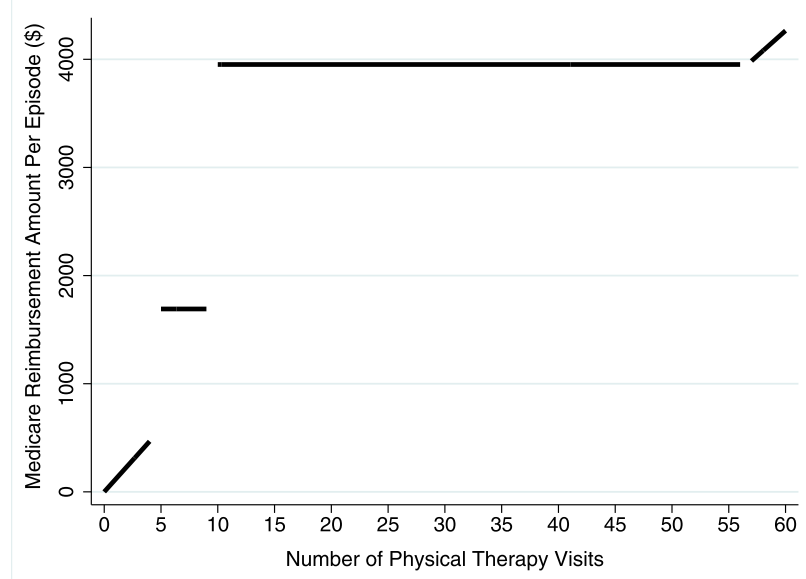

(a) Medicare Prospective Reimbursement Schedule in 2001

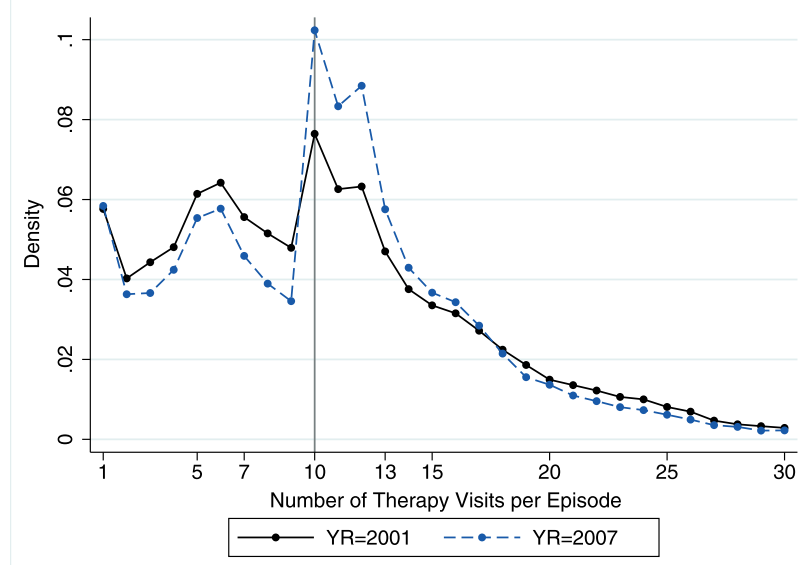

(b) Distribution of Number of Therapy Visits Provided in 2001 and 2007

Figure 2. Medicare home health therapy visits: (a) illustrates the Medicare prospective reimbursement schedule for a patient who received physical therapy visits from a home health agency located in Ann Arbor, MI, in 2001. Medicare would reimburse agencies for serving each patient every 60 days. This patient's case-mix group was $\mathrm{C} 1 \mathrm{~F} 3 \mathrm{~S} 0$ when the patient received fewer than 10 therapy visits, but switched to $\mathrm{C} 1 \mathrm{~F} 3 \mathrm{~S} 2$ once the number of therapy visits reached 10 . Because the patient's case-mix group changed, the payment system made about $\$ 2000$ extra payments once an agency had provided a 10th therapy visit in a 2-month-long treatment period. As a result, agencies had a strong incentive to provide at least 10 therapy visits each treatment period. Source of data in (b) is Medicare home health claims for 2001 and 2007.

There was also a large increase in marginal revenue at the fifth visit. This gave agencies an incentive to provide at least five visits per episode. Patients who received fewer than five visits (regardless of type of visits) became eligible for low-cost outlier payments, and the low-cost outlier payment rates are much lower than standard prospective payment rates (MedPAC, 2014). As seen in Figure 2(b), both in 2001 and 2007, there is a peak at the fifth visit. This peak is smaller than the peak at the 10th visit but still obvious. For simplicity, in this paper, we focus on agencies' targeting the 10th therapy visits only, but the same principle applies to the fifth. Analysis about targeting the fifth visit targeting the fifth visit is available upon request.

Second, agencies were increasingly likely to recertify an episode of care for each patient, independent of the patient's health. The PPS allows a patient to receive an unlimited number of episodes of care, as long as a physician recertifies the episode of care. Guidelines about recertification decisions-'beneficiaries must need 
part-time or intermittent skilled care to treat their illnesses or injuries and must be unable to leave their homes without considerable effort', (MedPAC, 2011) (p.177)—are ill-defined. Furthermore, physicians often make recertification decisions based only on information provided by the agency (MedPAC, 2011).

A recertified patient is more profitable for two reasons. Any fixed cost of learning about the patient and his or her health care needs have already been incurred. The other reason is selection. An agency has an incentive to recertify a more profitable patient; after 2 months, they will have information about which patients are more profitable. The number of episodes per home health patient increased from 1.6 in 2002 to 2.0 in 2009 (MedPAC, 2012). In 2011, responding to the increasing volume of episodes of care, Medicare required physicians to have a face-to-face encounter with a beneficiary for a complete evaluation before recertifying home health care (MedPAC, 2011).

These features embedded in the PPS made the home health industry highly profitable. The average Medicare home health care margins were about 17.5\% between 2001 and 2011 (MedPAC, 2014), which is much higher than the average Medicare hospital margin in 2011 (-5.5\%). The high profitability of the PPS combined with low entry costs attracted many new agencies to the market (MedPAC, 2010; Polsky et al., 2014). In addition, the market competition was relatively low initially because many agencies had exited the market between 1997 and 2000 (MedPAC, 2010).

Consistent with the organization theory predicting that for-profit firms tend to be more responsive to financial incentives (Sloan, 2000), most of the new agencies that entered the market under the PPS were for-profit agencies. Between 2001 and 2010, the number of for-profit agencies that entered the market $(n=5804)$ is stunningly higher than the number of nonprofit entrants $(n=252)$ (Figure 3$)$.

Despite the substantial financial incentives and market changes in the home health industry, only a few studies have examined the home health care under the PPS. Both the costs to Medicare and the likelihood of home health service use increased under the PPS (Huckfeldt et al., 2014; Choi and Davitt, 2009). The entrance of many new agencies to the market under the PPS made many markets more competitive (Choi and Davitt, 2009; MedPAC, 2011). Service quality increased with competition, except in extremely competitive markets where it decreased (Jung and Polsky, 2014). Certificate of Need programs for home health care lowered entry

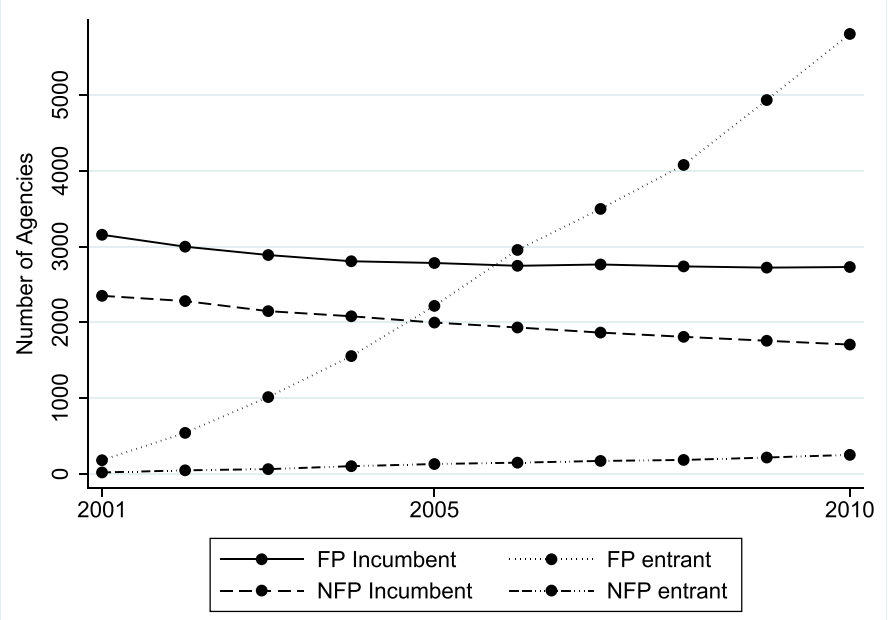

Figure 3. Number of for-profit and nonprofit agencies between 2001 and 2010. Source: Center for Medicare and Medicaid Services Provider of Services File. Notes: (1) We exclude government agencies due to their small number. (2) FP incumbent indicates for-profit agencies that had entered the market prior to the PPS; FP (For-profit) entrant indicates for-profit agencies that entered the market under the PPS; NFP (Nonprofit) incumbent indicate nonprofit agencies that had entered the market prior to the PPS; and NFP entrant indicates nonprofit agencies that entered the market under the PPS. (3) The increase in for-profit entrants was a primary driving force behind the drastic increase in the number of agencies between 2001 and 2010 
rates, but did not affect the overall quality of health care (Polsky et al., 2014). Hospital-affiliated agencies were more likely to admit sicker patients who require more home health visits (David et al., 2013).

Our paper highlights home health agencies' responsiveness to financial incentives embedded in the PPS and particularly focuses on entry status, which has not been studied before. That is, we examine differences in practice patterns between entrants and incumbents and changes in practice patterns by incumbents facing competition from entrants.

We also examine how agencies' for-profit status influenced practice patterns across entrants and incumbents. Only a few studies have analyzed the influence of ownership status on agencies' behaviors in the home health industry. Patients' length of enrollment in home health care was longer under the fee-for-service payment system if they were served by a for-profit agency (Grabowski et al., 2009; Han et al., 2007). For-profit agencies incurred higher expenditures, but provided worse quality of care under the PPS (Cabin et al., 2014).

\section{CONCEPTUAL FRAMEWORK}

The PPS provides strong incentives for home health agencies to adopt new practice patterns compared with the fee-for-service system. The response to the PPS incentives should be greater for entrants. Their adjustment costs are relatively low. In contrast, incumbents face relatively high adjustment costs because their employees, including nurses and physical therapists, have established practice patterns over a long period of time. Patients and their families would also not want to experience abrupt change in agencies' practice patterns. Thus, incumbents are less responsive to incentive to change practice patterns than entrants.

As discussed, most home health agency entrants were for-profits. Nonprofit agencies are only a small portion of entrants (4.2\% in 2010), but it is worthwhile to examine whether nonprofit entrants' practice patterns differed from their for-profit counterparts. Nonprofits have inherently different operational goals from forprofit agencies. For-profit agencies must distribute profits to shareholders and thus have a strong incentive to increase profits to survive in the market (Sloan, 2000; Kessler and McClellan, 2002). For-profit agencies are therefore expected to be more responsive to financial incentives and follow practice patterns that could increase profits. In contrast, nonprofit agencies do not have well-defined shareholders and thus have a weaker incentive to increase profits (Golberstein et al., 2009; Kessler and McClellan, 2002). Employees in nonprofits tend to be more altruistic decision-makers and thus would be less responsive to financial incentives (Duggan, 2000). Nonprofit agencies may maximize the quantity and quality of care instead of profits (Horwitz and Nichols, 2009; Newhouse, 1970). On the other hand, as argued by Weisbrod (1991), nonprofit agencies also could be solely motivated by profits. They are just for-profits in disguise that behave exactly like for-profits regardless of their ownership status. Norton and Staiger (1994) also find that for-profit and nonprofit hospitals are no different in their provision of charity care after adjusting for location. Nonprofit entrants could adopt new practice patterns to the same degree as for-profit entrants might. This framework leads to the following testable hypothesis:

\section{H1: Entrants were more likely to adopt profit-oriented practice patterns than incumbents, and the level of the adoption may vary depending on entrants' ownership type.}

On average, incumbents' adoption of practice patterns leading to high profits is expected to be lower because of their high adjustment costs. However, incumbents might also be affected by entrants in the same market. That is, if incumbents are located in a market where entrants more adroitly responded to the financial incentives in the PPS, the incumbents are then more likely to change their behavior facing competition from entrants. We thus expect to see entrants influence practice patterns among neighboring incumbents, which leads to our second hypothesis:

\section{H2: Entrants influenced practice patterns among neighboring incumbents.}




\section{EMPIRICAL STRATEGY}

\subsection{Practice patterns among entrants}

To examine the first hypothesis, we compare different types of agencies in their probability of using the two practice patterns. The dependent variable, $\operatorname{Pr}(\mathrm{Y})$, refers to the two practice patterns of our focus: (1) the likelihood of providing 10-13 therapy visits and (2) the likelihood of recertification. The cut point (10-13) for the number of therapy visits is based on the distribution of the number of therapy visits (Figure 2(b)). Given that agencies cannot significantly change the number of therapy visits for each patient, we also restrict the sample to episodes with 1-20 therapy visits for the regressions of the likelihood of receiving 10-13 therapy visits.

The independent variables of interest indicate agency type. We created a dummy variable that represents whether each agency is an entrant (i.e., entered the market under the PPS) or incumbent (i.e., entered the market prior to the PPS). We interacted this variable with each agency's ownership type. We consider this interaction because nonprofit entrants' practice patterns could differ from those of for-profit entrants. Our basic episode-level regression is shown in Equation (1).

$$
\begin{aligned}
\operatorname{Pr}\left(Y_{k i j h t}\right)= & \beta_{0}+\beta_{1} \text { EntryPPS }_{j h}+\beta_{2} \text { NonProfit }_{j h t} \\
& +\beta_{3} \text { EntryPPS }_{j h} \times \text { NonProfit }_{j h t}+\beta_{4} \text { Agency }_{j h t}+\beta_{5} \text { Patient }_{k i j h t} \\
& +\beta_{6} \text { Seasonality }_{k}+\beta_{7} \text { HHI }_{j t}+H R R_{h}+\tau_{t}+\varepsilon_{k i j h t}
\end{aligned}
$$

where $k, i, j, h$, and $t$ refer to episode, patient, agency, market, and year, respectively. EntryPPS is an indicator representing whether each agency entered the market under the PPS. NonProfit refers to an indicator of each agency's ownership status with a value of 1 for nonprofit agencies and 0 for for-profits.

Agency represents each agency's basic characteristics, including facility-based status (whether an agency is facility-affiliated (e.g., hospital-nursing or skilled-nursing home-based) or free-standing-reference group), years of operation, and number of employed nurses, physical therapists, and home health aides. Patient is a vector of patient demographic characteristics, including age, race, gender, and Medicare Buy-In program participation status (a proxy of being low-income given that the Medicaid program helps pay Medicare premiums for low-income beneficiaries) (FamiliesUSA, 1999). Patient also includes each patient's health status such as most frequent health diagnoses, level of clinical and functional limitations, and indicators for where each patient stayed right before the home health admission (stayed in a hospital or nursing home-reference group, stayed home, or was referred from another home health agency). Unfortunately, we do not have sufficiently detailed individual health status data to examine whether an agency was more likely to recertify more profitable patients. Thus, we do not consider how a patient's profitability affected her likelihood of being recertified. We also control for Seasonality, an indicator variable for the first (reference group), second, third, and last quarter of each year. Anecdotally, Medicare beneficiaries' use of home health care varies depending on the season, which may affect an agency's behaviors.

HHI is the agency-level Herfindahl-Hirschman index, which measures the level of market competitiveness faced by each agency. We define the HHI using the approach of Zwanziger and Melnick (1988). The formula is a weighted average of county-level HHIs, weighted by the fraction of each agency's patients in each county (see Appendix (Supporting Information) for details). We also control for hospital referral region (HRR) using fixed effects. HRRs were developed by the Dartmouth Atlas of Health Care as a measure of the local market for home health care. The Dartmouth Atlas of Health Care divided the United States into 306 HRRs such that each HRR contains major referral hospitals in which both major cardiovascular surgical procedures and neurosurgery are performed (Dartmouth Atlas, 2012). Individual HRRs reflect patient admission patterns and can thus overcome limitations of the arbitrarily use of political boundaries, such as states and counties, to define markets (Chandra and Staiger, 2007). Although originally developed to identify a hospital market, HRR works well to define a home health market because HRR represents the market for tertiary medical care and is closely linked to geographic variation in health care usage. Using HRR for a home health market is also sensible because many 
home health patients have had prior hospital stays. Finally, we include year dummy variables, $\tau$, to control for time trends in the outcome variable.

The first coefficient of interest, $\beta_{1}$, measures the difference between for-profit entrants and incumbents in their practice patterns. We expect $\beta_{1}$ to be positive, according to H1. Another coefficient of interest, $\beta_{3}$, measures the difference between nonprofit entrants and incumbents in their practice patterns, relative to the difference between for-profit entrants and incumbents. We estimate separate linear probability models for each dependent variable. In fact, all results are essentially the same when we estimate probit models instead. However, we prefer the individual ordinary least squares regression (OLS) results because of the more straightforward inference with the interaction term estimates (Ai and Norton, 2003; Karaca-Mandic et al., 2012; Norton et al., 2004). Standard errors are clustered at the HRR level.

\subsection{Influence of neighboring entrants on practice patterns among incumbents}

To examine our second hypothesis, we created a sample of episodes served by incumbents while excluding episodes in HRRs with no entrants. We then evaluated how the practice patterns of entrants affected incumbents in the same market. Identification is difficult because an individual entity's behavior can change jointly with an average group behavior (Manski, 1993, 2000; Gaviria and Raphael, 2001; Norton et al., 2003; Sorensen, 2006). To avoid this identification difficulty, we follow the approach of the studies that used one-period-lagged reference group information (Pollak, 1976; Alessie and Kapteyn, 1991; Woittiez and Kapteyn, 1998). Using a one-period lag is also justifiable because it could take time for agencies to identify profitable practice patterns and adjust practice patterns.

We stratify the sample by agency ownership and estimate regression (2) separately for episodes served by for-profit and nonprofit agencies because for-profit and nonprofit agencies' responses to entrants' practice patterns could be different because of their different operational goals. The basic episode-level regression takes the following form:

$$
\begin{aligned}
\operatorname{Pr}\left(Y_{k i j h t}\right)= & \beta_{0}+\beta_{1} \overline{Y_{h t-1}^{\text {newfp }}}+\beta_{2} \overline{Y_{h t-1}^{\text {existingfp }}}+\beta_{3} \overline{Y_{h t-1}^{\text {newnp }}}+\beta_{4} \overline{Y_{h t-1}^{\text {existingnp }}} \\
& +\beta_{5} \text { Agency }_{j h t}+\beta_{6} \text { Patient }_{k i j h t}+\beta_{7} \text { Seasonality }_{k}+\beta_{8} H H I_{j t} \\
& + \text { HRR }_{h}+\tau_{t}+\varepsilon_{k i j h t}
\end{aligned}
$$

where $\overline{Y_{h t-1}^{\text {newfp }}}$ and $\overline{Y_{h t-1}^{\text {existingfp }}}$ are the average specific practice pattern $(Y)$ of for-profit entrants and incumbents in HRR $h$ in year $t-1$, respectively. Likewise, $\overline{Y_{h t-1}^{\text {newnp }}}$ and $\overline{Y_{h t-1}^{\text {existingnp }}}$ are the proportion of specific practice pattern of nonprofit entrants and incumbents in HRR $h$ in year $t-1$, respectively.

A relatively small number of nonprofit agencies $(n=252)$ entered the market under the PPS. This means that there are only a small number of episodes that occurred in HRRs that experienced entry by nonprofits in the main analysis (e.g., only 83 out of 306 HRRs had nonprofit entrants in 2006). To avoid a substantial reduction in sample size, we also restrict the sample to HRRs with no nonprofit entrants and run regression (3) without

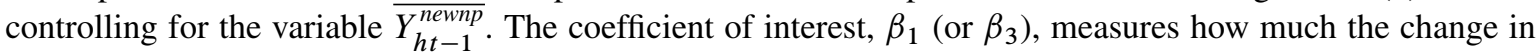
the average practice patterns among for-profit (or nonprofit) entrants in HRR-affected practice patterns among incumbents in the same HRR. Standard errors are clustered at the HRR level.

\section{DATASETS}

We use 2001 to 2007 data from three sources: the CMS 5\% Limited Data Set-Denominator File, the CMS 5\% Limited Data Set-Home Health Agency File, and the CMS Provider of Services File. The first dataset contains 
basic demographic information on 5\% of all Medicare beneficiaries enrolled in a given year so the 7 years of data create a panel dataset. The second dataset is a panel of 5\% of Medicare beneficiaries who received home health services and contains information on their use of those services (CMS, 2012). The third dataset is a panel of all Medicare-certified home health agencies across the nation and includes their basic information including location, ownership type, and date of initial Medicare certification. We combine all three datasets, creating a patient-agency linked, unbalanced panel dataset. Each observation in this dataset corresponds to a patient's unique episode of care.

We limit the sample to Medicare beneficiaries who are age 65 years or older. We also drop health maintenance organization (HMO)-enrolled beneficiaries because Medicare HMOs were not directly influenced by Medicare reimbursement system changes. We further exclude episodes in which home health care was interrupted because a patient was transferred or discharged to another health care setting (e.g., hospital, intermediate care facility, nursing home, and hospice), transferred to another agency, or died. We drop the few episodes treated by government home health agencies (4.68\% of all episodes in 2007). Finally, we drop episodes served by agencies in their entry year, because the information is only for a partial year. These selection criteria created an unbalanced panel dataset with 1,140,543 patient-episode observations on 458,754 unique patients. See Table I for summary statistics of the main variables.

Table I. Summary statistics of outcomes and patient and facility characteristics in for-profit and nonprofit agencies in 2007

\begin{tabular}{|c|c|c|c|c|}
\hline & \multicolumn{2}{|c|}{ For-profit agencies } & \multicolumn{2}{|c|}{ Nonprofit agencies } \\
\hline & Mean (SD) & Observations & Mean (SD) & Observations \\
\hline \multicolumn{5}{|l|}{ Outcomes } \\
\hline $\operatorname{Pr}(10 \leq$ Therapy visit $\leq 13)$ & 0.41 & 56,365 & 0.23 & 40,150 \\
\hline $\operatorname{Pr}($ Recertification $)$ & 0.52 & 122,580 & 0.29 & 71,990 \\
\hline \multicolumn{5}{|l|}{ Patient characteristics } \\
\hline Age (65-99) & $79.47(7.87)$ & 63,393 & $79.48(7.76)$ & 50,273 \\
\hline \multicolumn{5}{|l|}{ Race } \\
\hline Pr(White) & 0.80 & 63,393 & 0.89 & 50,273 \\
\hline $\operatorname{Pr}($ Black $)$ & 0.20 & 63,393 & 0.11 & 50,273 \\
\hline $\operatorname{Pr}($ Other race $)$ & 0.0015 & 63,393 & 0.0017 & 50,273 \\
\hline $\operatorname{Pr}($ Female $)$ & 0.66 & 63,393 & 0.64 & 50,273 \\
\hline $\operatorname{Pr}($ Buy-in participation) & 0.26 & 63,393 & 0.16 & 50,273 \\
\hline \multicolumn{5}{|l|}{ Functional limitation } \\
\hline $\operatorname{Pr}($ Min $)$ & 0.028 & 122,580 & 0.042 & 71,990 \\
\hline $\operatorname{Pr}($ Low $)$ & 0.20 & 122,580 & 0.22 & 71,990 \\
\hline $\operatorname{Pr}(\mathrm{Mod})$ & 0.54 & 122,580 & 0.54 & 71,990 \\
\hline $\operatorname{Pr}($ High $)$ & 0.15 & 122,580 & 0.11 & 71,990 \\
\hline $\operatorname{Pr}(\operatorname{Max})$ & 0.079 & 122,580 & 0.077 & 71,990 \\
\hline \multicolumn{5}{|l|}{ Agency characteristics } \\
\hline $\operatorname{Pr}($ Facility-based $)$ & 0.031 & 4,870 & 0.52 & 1,738 \\
\hline Years of operation & $9.54(8.56)$ & 4,870 & $23.09(11.06)$ & 1,738 \\
\hline No. of nurses & $9.14(65.95)$ & 4,870 & $17.74(42.00)$ & 1,738 \\
\hline No. of physical therapists & $2.16(10.28)$ & 4,870 & $4.42(9.00)$ & 1,738 \\
\hline No. of home health aides & $5.82(36.96)$ & 4,870 & $8.03(21.56)$ & 1,738 \\
\hline Agency-level HHI & $0.12(0.12)$ & 4,870 & $0.25(0.17)$ & 1,738 \\
\hline
\end{tabular}

SD, standard deviation; HHI, Herfindahl-Hirschman index.

The number of observations varies depending on whether variation of each variable comes from episode-level, patient-level, or agency-level.

'Facility-based' is a dummy variable indicating whether an agency is hospital-nursing or skillednursing home-affiliated or free-standing. 


\section{RESULTS}

\subsection{Practice patterns among entrants}

For-profit entrants were more responsive to financial incentives embedded in the PPS than were for-profit incumbents. As seen in Table II, column 1, a patient's likelihood of receiving 10-13 therapy visits is higher by $6.7 \%$ if the patient receives the visits from a for-profit entrant compared with an incumbent. Given that for-profit agencies' average likelihood of providing $10-13$ therapy visits is $41 \%$ in 2007 , a $6.7 \%$ difference is relatively substantial. The interaction term between indicators of agency ownership and entrant is insignificant, which

Table II. Practice patterns in incumbents and entrants

\begin{tabular}{|c|c|c|}
\hline Covariate & (1) $\operatorname{Pr}(10 \leq$ Therapy visit $\leq 13)$ & (2) $\operatorname{Pr}($ Recertification) \\
\hline \multicolumn{3}{|l|}{ Agency characteristics } \\
\hline Nonprofit & $-0.0425^{* * *}$ & $-0.0340^{* * *}$ \\
\hline (vs for-profit) & $(0.0053)$ & $(0.0079)$ \\
\hline \multirow[t]{2}{*}{ Entry under PPS } & $0.0667 * * *$ & $0.029 * *$ \\
\hline & $(0.0099)$ & $(0.012)$ \\
\hline Entry under PPS & -0.014 & -0.016 \\
\hline$\times$ Nonprofit & $(0.017)$ & $(0.018)$ \\
\hline \multirow[t]{2}{*}{ Years of operation } & $-0.00069 * * *$ & -0.00055 \\
\hline & $(0.00019)$ & $(0.00037)$ \\
\hline Facility-based & $-0.0231 * * *$ & $-0.0406 * * *$ \\
\hline (vs free-standing) & $(0.0044)$ & $(0.0067)$ \\
\hline \multirow{2}{*}{ Agency-level HHI } & 0.023 & $0.213 * *$ \\
\hline & $(0.015)$ & $(0.035)$ \\
\hline \multicolumn{3}{|l|}{ Patient characteristics } \\
\hline \multirow[t]{2}{*}{ Age } & $0.0087 * * *$ & $0.0042 * *$ \\
\hline & $(0.0015)$ & $(0.0020)$ \\
\hline \multirow[t]{2}{*}{ Age-squared } & $0.000052 * * *$ & $0.000043^{* * *}$ \\
\hline & $(0.000000)$ & $(0.000013)$ \\
\hline \multirow{2}{*}{\multicolumn{3}{|c|}{$\begin{array}{l}\text { Race } \\
\text { (White) }\end{array}$}} \\
\hline & & \\
\hline \multirow[t]{2}{*}{ Black } & $0.0230 * * *$ & $0.0215^{* * *}$ \\
\hline & $(0.0054)$ & $(0.0054)$ \\
\hline \multirow[t]{2}{*}{ Others } & 0.0061 & -0.0093 \\
\hline & $(0.0148)$ & $(0.0148)$ \\
\hline \multirow[t]{2}{*}{ Female } & $0.0112 * * *$ & -0.0023 \\
\hline & $(0.0015)$ & $(0.0022)$ \\
\hline \multirow[t]{2}{*}{ Buy-in participation } & $0.00140 * * *$ & $0.00614 * * *$ \\
\hline & $(0.00040)$ & $(0.00042)$ \\
\hline \multicolumn{3}{|l|}{$\begin{array}{l}\text { Functional limitation } \\
\text { (Min) }\end{array}$} \\
\hline \multirow[t]{2}{*}{ Low } & $0.0994 * * *$ & $0.0330 * * *$ \\
\hline & $(0.0044)$ & $(0.0030)$ \\
\hline \multirow[t]{2}{*}{ Mod } & $0.1422 * * *$ & $0.0587 * * *$ \\
\hline & $(0.0039)$ & $(0.0038)$ \\
\hline \multirow{2}{*}{ High } & $0.1424 * * *$ & $0.1047 * * *$ \\
\hline & $(0.0054)$ & $(0.0042)$ \\
\hline \multirow[t]{2}{*}{ Max } & $0.0812 * * *$ & $0.2308^{* * *}$ \\
\hline & $(0.0054)$ & $(0.0064)$ \\
\hline Observations & 550,460 & $1,140,543$ \\
\hline
\end{tabular}

PPS, prospective payment system.

Other control variables include agency characteristics (number of nurses, physical therapists, and home health aides), patient characteristics (indicators for where each patient stayed right before the home health admission, major health conditions, and level of clinical limitation), seasonality, and year and hospital referral region fixed effects.

Equations are estimated using an ordinary least-squares regression.

Standard errors shown in parenthesis are clustered on hospital referral region. In column

1 , we restrict the sample to episodes that provided 1-20 therapy visits.

$* p \leq 0.1 ; * * p \leq 0.05 ; * * * p \leq 0.01$. 
suggests that the discrepancy between nonprofit entrants and incumbents in their likelihood of providing 10-13 therapy visits was not statistically different from the corresponding discrepancy between for-profit entrants and incumbents. We find the similar pattern for recertification except that the effect is smaller. For-profit entrants are more likely to recertify another episode of care by $2.9 \%$ compared with for-profit incumbents. Given the forprofits' mean likelihood of recertification in 2007 (52\%), the difference is relatively small but still meaningful. This practice pattern difference between entrants and incumbents is also found among nonprofits. For the full model estimation, please see Appendix (Supporting Information) Table I.

As a sensitivity check, we run the same set of regressions but with different outcome variables. Given that the reimbursement significantly increased at the 10th therapy visit, providing seven to nine visits represents relatively unprofitable practice patterns. We therefore expect to see that entrants are less likely to provide seven to nine visits. The regression results are consistent with this prediction (see Appendix Table II, column 1). Both for-profit and nonprofit entrants' tendency of providing seven to nine therapy visits is smaller than their counterpart incumbents. We also run the same regression with the outcome variables with different cutoff points: the likelihood of providing 10,10-11, and 10-12 therapy visits. All the results are the same qualitatively, although the magnitude of the coefficient changes slightly (see Appendix Table II, columns 2-4).

\subsection{Influence of neighboring entrants on practice patterns among incumbents}

We find strong effects of the influence of entrants on provision of 10-13 therapy visits among for-profit incumbents, but not for nonprofit incumbents. When we limit the sample to HRRs that had no nonprofit entrants, changes in for-profit incumbents' provision of 10-13 therapy visits is positively correlated with the changes in for-profit entrants' behavior in the previous year (see column 1 in Table III). This result is consistent with our prediction. More specifically, if a for-profit incumbent is located in an HRR that experienced a $1 \%$ higher growth in the likelihood of providing 10-13 therapy visits among for-profit entrants, then the incumbent's likelihood of providing 10-13 visits increases by $4.3 \%$. Even when we limit the sample to only HRRs that had nonprofit entrants, there remains a positive association in providing 10-13 visits between for-profit incumbents and entrants, but the relationship is less statistically significant than that in column 1 . This might be driven by

Table III. Influence of neighboring entrants on practice patterns among incumbents

\begin{tabular}{|c|c|c|c|c|c|c|c|c|}
\hline \multirow[b]{3}{*}{ Covariate } & \multicolumn{4}{|c|}{$\operatorname{Pr}\left(10 \leq V^{T} \leq 13\right)$} & \multicolumn{4}{|c|}{$\operatorname{Pr}$ (Recertified) } \\
\hline & \multicolumn{2}{|c|}{ For-profit } & \multicolumn{2}{|c|}{ Nonprofit } & \multicolumn{2}{|c|}{ For-profit } & \multicolumn{2}{|c|}{ Nonprofit } \\
\hline & $(1)$ & (2) & (3) & (4) & (5) & (6) & (7) & (8) \\
\hline $\mathrm{E}$ (FP incumbent) & $\begin{array}{c}-0.065 \\
(0.052)\end{array}$ & $\begin{array}{c}-0.19^{*} \\
(0.11)\end{array}$ & $\begin{array}{c}0.016 \\
(0.033)\end{array}$ & $\begin{array}{c}0.067 \\
(0.099)\end{array}$ & $\begin{array}{l}0.280^{* * *} \\
(0.058)\end{array}$ & $\begin{array}{l}0.372 * * * \\
(0.044)\end{array}$ & $\begin{array}{l}0.070 * * * \\
(0.025)\end{array}$ & $\begin{array}{l}0.152 \text { *** } \\
(0.049)\end{array}$ \\
\hline $\mathrm{E}$ (FP entrant) & $\begin{array}{l}0.043^{* * * *} \\
(0.013)\end{array}$ & $\begin{array}{c}0.066^{*} \\
(0.035)\end{array}$ & $\begin{array}{r}-0.017 \\
(0.011)\end{array}$ & $\begin{array}{r}-0.049 \\
(0.036)\end{array}$ & $\begin{array}{c}-0.0109 \\
(0.0174)\end{array}$ & $\begin{array}{c}-0.093 * * \\
(0.037)\end{array}$ & $\begin{array}{c}0.011 \\
(0.011)\end{array}$ & $\begin{array}{r}-0.114^{*} \\
(0.067)\end{array}$ \\
\hline $\mathrm{E}$ (NFP incumbent) & $\begin{array}{c}0.011 \\
(0.033)\end{array}$ & $\begin{array}{c}0.048 \\
(0.052)\end{array}$ & $\begin{array}{c}0.010 \\
(0.058)\end{array}$ & $\begin{array}{c}0.023 \\
(0.112)\end{array}$ & $\begin{array}{c}0.029 \\
(0.024)\end{array}$ & $\begin{array}{c}0.046 \\
(0.069)\end{array}$ & $\begin{array}{l}0.183 * * * \\
(0.051)\end{array}$ & $\begin{array}{c}0.039 \\
(0.110)\end{array}$ \\
\hline $\mathrm{E}$ (NFP entrant) & & $\begin{array}{c}0.014 \\
(0.013)\end{array}$ & & $\begin{array}{c}0.0034 \\
(0.0219)\end{array}$ & & $\begin{array}{c}-0.028 \\
(0.020)\end{array}$ & & $\begin{array}{c}-0.018 \\
(0.038)\end{array}$ \\
\hline Observations & 112,186 & 32,685 & 98,177 & 21,506 & 249,568 & 78,412 & 193,914 & 42,977 \\
\hline
\end{tabular}

We ran all regressions, separately by agency ownership type.

$\mathrm{E}$ (FP Incumbent) and E(FP Entrants) indicate the average specific practice pattern of for-profit entrants and incumbents in the same hospital referral region (HRR) in the previous year, respectively.Likewise, E(NFP Incumbent) and E(NFP Entrants) indicate the average specific practice pattern of nonprofit entrants and incumbents in the same HRR in the previous year, respectively.

Other control variables include patient characteristics (age, age-squared, race, gender, participation in Medicare Buy-In Program, indicators for where each patient stayed right before the home health admission, major health conditions, and level of functional and clinical limitation), agency characteristics(number of registered nurses, physical therapists, and home health aides, years of operation, and facilitybased status), Herfindahl-Hirschman Index, seasonality, and HRR and year fixed effects.

Equations are estimated using an ordinary least-squares regression.

Standard errors shown in parenthesis are clustered on HRR. In regressions of columns 1-4, we restrict the sample to episodes that provided $1-20$ therapy visits.

$* p \leq 0.1 ; * * \leq 0.05 ; * * * p \leq 0.01$. 
a higher standard error because of a relatively small sample size in column 2 . We do not find the same pattern among nonprofits: there is no positive relationship in providing 10-13 visits between nonprofit entrants and incumbents (Table III, columns 3 and 4).

There is no positive relationship in recertification between entrants and incumbents in regressions when we limit the sample to HRRs that had no nonprofit entrants (Table III, columns 5 and 7). Interestingly, however, once we limit the sample to HRRs that had nonprofit entrants, we find a negative relationship in recertification between entrants and incumbent (Table III, columns 6 and 8). We also find that if the average likelihood of recertification among for-profit incumbents in the previous year was higher, then for-profit and nonprofit incumbents in the same market were also more likely to recertify an episode of care 1 year later.

In the original estimation specification, we excluded episodes in HRRs with no entrants because we want to examine the influence of entrants' practice patterns on neighboring incumbents. It could be interesting to compare the incumbents in markets with and without entrants. We predict that the probability of recertification and providing 10-13 therapy visits is higher for incumbents in markets with entrants compared with incumbents in markets without entrants. This prediction turns out to be true. The average likelihood of providing 10-13 therapy visits is 0.35 and 0.26 among incumbents located in markets with and without entrants, respectively. The corresponding values were 0.41 and 0.33 for the average likelihood of recertification. This discrepancy in incumbents' practice patterns still exists even after controlling for other factors that could influence practice patterns.

\section{DISCUSSION}

Our study has produced a number of policy-relevant findings. First, we have shown that home health agencies respond to financial incentives. Agencies change the number of visits and whether they recertify patients based on these incentives. The policy implication is that we need to be careful about how we design incentives. It is important to think through possible unintended consequences of policies like non-linear reimbursement schedules and weakly monitored recertification. In hindsight, this conclusion may appear obvious, but at the time CMS implemented these policies, they believed that the PPS would control future home health care expenditures. The policies did not achieve that for predictable reasons.

Second, our findings suggest that entrants, with lower adjustment costs, were more responsive to financial incentives of the PPS than were incumbents. Policy-makers generally are concerned with how policies will affect those already in the market. In this case, much of the increase in total expenditures can be attributed to entrants who were more likely to adopt the practice patterns leading to higher Medicare reimbursements. New entry may be good for overall patient welfare, if patients can be treated better at home than in more restricted and expensive settings. However, entry raised expenditures on home health care.

Third, entrants' behaviors were the same by ownership type. We found that nonprofit entrants' practice patterns were not different from those of for-profit agencies (similar to the result by Norton and Staiger (1994) about hospitals). Although some of the statistical insignificance in results may have been driven by the small number of nonprofit entrants, our result is an important reminder that nonprofit providers also choose to behave strategically.

Fourth, we found that entrants' practice patterns affected the incumbents' in the same market. This is another indirect effect of the financial incentives. Financial incentives directly affected behavior of incumbents and the number of entrants, but it also indirectly affected behavior of incumbents through the entrants' behavior. This result highlights that providers do not operate in a vacuum but instead in markets with other providers. To fully understand the effects of any policy, it is important to know how the policy varies with the level of interactions among providers.

The results should be understood in light of the limitations of the study. First, we cannot perfectly take into account patient selection among incumbents and entrants. The models control for patients' main diagnoses and functional limitations but cannot control for unmeasured health status, which could be correlated with choice of agency and therefore bias estimates. However, the bias is less of a concern for examining agencies' target of 
10 or more therapy visits because it is hard to imagine patient health status that requires exactly 10-13 therapy visits per episode. Another limitation is that we use a 5\% sample of Medicare home health patients. When the number of episodes per agency is small, those episodes may not be representative of the agency. In addition, our analysis may have excluded episodes by small agencies. However, excluded agencies are likely to be entrants, which are relatively small compared with incumbents. Given that we find entrants were more likely to adopt strategic practice patterns, excluding those small agencies implies that our results are conservative.

\section{CONCLUSION}

Prior research has shown that home health agencies strategically adopted two specific practice patterns to take advantage of Medicare policies: provide at least 10 therapy visits to get an enormous marginal payment and recertify patients for additional episodes. We identify policy-relevant heterogeneity in the adoption of those strategic behaviors between entrants and incumbents: entrants were more likely to strategically adopt practice patterns than were incumbents. We also find that for-profit incumbents mimicked one of the practice patterns following entrants in the same market. Our findings suggest that it is important to understand the heterogeneity in providers' behavior and how firms interact with each other in the same market. These findings help explain the rapid rise in expenditures in the home health care market.

\section{CONFLICT OF INTEREST}

The authors have no potential conflicts of interest to declare with respect to this article.

\section{ACKNOWLEDGEMENTS}

This project was generously supported by the Rackham Graduate School of the University of Michigan, the Fahs-Beck Fund for Research and Experimentation, the Blue Cross Blue Shield of Michigan Foundation, and Ewha Womans University. We are grateful for helpful comments from Guy David, University of Michigan seminar participants, and American Society of Health Economists 2014 participants.

\section{REFERENCES}

Ackerly DC, Grabowski DC. 2014. Post-acute care reform beyond the ACA. New England Journal of Medicine 370(8): 689-691.

Ai C, Norton EC. 2003. Interaction terms in logit and probit models. Economic Letters 80(1): 123-129.

Alessie R, Kapteyn A. 1991. Habit formation, interdependent preferences and demographic effects in the almost ideal demand system. Economic Journal 101: 404-419.

Benjamin AE. 1993. An historical perspective on home care policy. The Millbank Quarterly 71(1): 129-166.

Burgess JF, Carey K, Young GJ. 2005. The effect of network arrangements on hospital pricing behavior. Journal of Health Economics 24: 391-405.

Cabin W, Himmelstein DU, Siman ML, Woolhandler S. 2014. For-profit Medicare home health agencies' costs appear higher and quality appears lower compared to nonprofit agencies. Health Affairs 33(8): 1460-1465.

Chandra A, Staiger D. 2007. Productivity spillovers in health care: evidence from the treatment of heart attacks. Journal of Political Economy 115(1): 103-140.

Choi S, Davitt J. 2009. Changes in the Medicare home health care market: the impact of reimbursement policy. Medical Care 47(3): 302-309.

CMS. 2012. Standard analytical files-LDS.

Dartmouth Atlas. 2012. The dartmouth atlas of health care. www.dartmouthatlas.org.

David G, Rawley E, Polsky D. 2013. Integration and task allocation: evidence from patient care. Journal of Economics \& Management Strategy 22(3): 617-639.

Duggan MG. 2000. Hospital ownership and public medical spending. Quarterly Journal of Economics 115(4): $1343-1373$. 
FamiliesUSA. 1999. The Medicare buy-in. www.familiesusa.org.

Gaviria A, Raphael S. 2001. School-based peer effects and juvenile behavior. The Review of Economics and Statistics 83(2): 257-268.

Golberstein E, Grabowski D, Langa K, Chernew M. 2009. Effect of Medicare home health care payment on informal care. Inquiry 46: 58-71.

Grabowski D, Huskamp H, Stevenson D, Keating N. 2009. Ownership status and home health care performance. Journal of Aging and Society 21(2): 130-143.

Han B, McAuley WJ, Remsburg RE. 2007. Agency ownership, patient payment source, and length of service in home care, 1992-2000. Gerontologist 47(4): 438-446.

HCFA. 2000. Medicare program; prospective payment system for home health agencies; final rule, Vol. 65, No. 128.

Horwitz JR, Nichols A. 2009. Hospital ownership and medical services: market mix, spillover effects, and nonprofit objectives. Journal of Health Economics 28(5): 924-937.

Huckfeldt Peter, Sood N, Escarce JJ, Grabowski DC, Newhouse JP. 2014. Effects of Medicare payment reform: evidence from the home health interim and prospective payment systems. Journal of Health Economics 34(0): 1-18.

Jung K, Polsky D. 2014. Competition and quality in home health care markets. Health Economics 23(3): 298-313.

Karaca-Mandic P, Norton EC, Dowd B. 2012. Interaction terms in nonliner models. Health Services Research 47(1): 255-274.

Kessler DP, McClellan MB. 2002. The effects of hospital ownership on medical productivity. Rand Journal of Economics 33(3): 488-506.

Keeler EB, Melnick G, Zwanziger J. 1999. The changing effects of competition on non-profit and for-profit hospital pricing behavior. Journal of Health Economics 18: 69-86.

Konetzka RT, Karon SL, Potter D. 2012. Users of medicaid home and community-based services are especially vulnerable to costly avoidable hospital admissions. Health Affairs 31(6): 1167-1175.

Lichtenberg F. 2012. Is home health care a substitute for hospital care. Home Health Care Service Quarterly 31(1): 84-109.

Manski CF. 1993. Identification of endogenous social effects: the reflection problem. The Review of Economic Studies 60(3): 531-542.

Manski CF. 2000. Economic analysis of social interactions. Journal of Economic Perspectives 14(3): 115-136.

MedPAC. 2010. Report to the congress: Medicare payment policy. Technical Report, Washington, D.C.

MedPAC. 2011. Report to the congress: Medicare payment policy. Technical Report, Washington, D.C.

MedPAC. 2012. Report to the congress: Medicare payment policy. Technical Report, Washington, D.C.

MedPAC. 2013. Report to the congress: Medicare payment policy. Technical Report, Washington, D.C.

MedPAC. 2014. Report to the congress: Medicare payment policy. Technical Report, Washington, D.C.

Newhouse JP. 1970. Toward a theory of nonprofit institution: an economic model of a hospital. The American Economic Review 60(1): 64-74.

Norton EC, Lindrooth RC, Ennett ST. 2003. How measures of perception from survey data lead to inconsistent regression results: evidence from adolescent and peer substance use. Health Economics 12(2): 139-148.

Norton EC, Staiger DO. 1994. How hospital ownership affects access to care for the uninsured. The RAND Journal of Economics 25(1): 171-185.

Norton EC, Wang H, Ai C. 2004. Computing interaction effects and standard errors in logit and probit models. Stata Journal 4(2): $154-167$

Pollak RA. 1976. Interdependent preferences. American Economic Review 66(3): 309-320.

Polsky D, David G, Yang J, Kinosian B, Werner RM. 2014. The effect of entry regulation in the health care sector: the case of home health. Journal of Public Economics 110(0): 1-14.

Sloan FA. 2000. Not-for-profit ownership and hospital behavior, In Handbook of Health Economics vol. 1, Part B, Culyer AJ, Newhouse JP (eds), Elsevier: Amsterdam The Netherlands; 1141-1174.

Sorensen Alan. 2006. Social learning and health plan choice. Rand Journal of Economics 37(4): 929-945.

Weisbrod Burton. 1991. The Nonprofit Economy. Havard University Press: Cambridge, MA.

Woittiez Isolde, Kapteyn Arie. 1998. Social interactions and habit formation in a model of female labour supply. Journal of Public Economics 70(2): 185-205.

Zwanziger J, Melnick G. 1988. The effects of hospital competition and the Medicare PPS program on hospital cost behavior in California. Journal of Health Economics 7(4): 301-320.

\section{SUPPORTING INFORMATION}

Additional supporting information may be found in the online version of this article at the publisher's website. 